\title{
A INSTITUCIONALIZAÇÃO DO COMÉRCIO INTERNACIONAL SOB A ÓTICA DA ORGANIZAÇÃO MUNDIAL DO COMÉRCIO E A JUSTIÇA COMERCIAL
}

\author{
Monique de Medeiros Fidelis ${ }^{1}$
}

\section{RESUMO}

A presente pesquisa apresenta a possibilidade da Organização Mundial do Comércio (OMC) inferir na realidade social dos países, em especial, os em desenvolvimento e como se dá a busca pela justiça comercial. Ao considerar a realidade da disparidade social e a busca por relações de trocas comerciai pautadas na busca por justiça comercial, o estudo traça um panorama sobre esses aspectos ao aborda-los conjuntamente na busca por uma institucionalização do comércio internacional. O método de pesquisa utilizado foi o indutivo e os meios foram bibliográficos. Quanto aos fins, a pesquisa foi descritiva e explicativa, com resultados em forma de textos.

Palavras-chave: Organização Mundial do Comércio; Direito Internacional; Justiça Comercial; Institucionalização do Comércio: Justiça

\section{THE INSTITUTIONALIZATION OF THE INTERNATIONAL TRADE UNDER THE VIEW OF THE WORLD TRADE ORGANIZATION AND JUSTICE IN TRADE}

\begin{abstract}
This research presents the possibility of the World Trade Organization (WTO) to infer in the social reality of countries, especially those in development, and how the search for justice in trade. When considering the reality of social disparity and the search for trade relations based on the search for commercial justice, the study provides an overview of these aspects by addressing them together in the search for an institutionalization of international trade. The research method used was inductive and the means were bibliographic. The research was descriptive and explanatory. The results were exposed in the form of texts.
\end{abstract}

Keywords: World Trade Organization; International Law; Justice in Trade; Institutionalization of Trade; Justice

\section{INTRODUÇÃO}

A interconectividade dos acontecimentos históricos com a realidade atual é clara e sua constatação não é algo recente. O intercâmbio de informações tem alcançado novos patamares diariamente pela troca dos saberes que ocorrem em rede à nível mundial. Essa nova dinâmica trouxe também o desafio de se identificar a realidade não apenas como um produto do meio, mas da história como um todo.

\footnotetext{
${ }^{1}$ Mestra e Doutoranda em Direito Internacional pela Universidade Federal de Santa Catarina
} 
Isso permite um olhar para a gênese de organizações internacionais como fator determinante para a compreensão das realidades que geram indagações científicas sobre o porquê de serem como são.

Nesse ínterim, o presente artigo teve como problema identificar como o nascimento da Organização Mundial do Comércio inferiu na realidade social de países em desenvolvimento e como se dá a busca pela justiça comercial diante desse cenário.

A hipótese, que foi confirmava, apontava que há no escopo dos objetivos da OMC a finalidade de promoção de justiça comercial devendo ter um olhar atencioso ao grupo países não hegemônicos. No entanto, com a realidade de disparidade social, esse objetivo ainda necessita de esforços para o seu alcance.

Para que a hipótese servisse de solução para o problema pesquisado, objetivou-se, primeiramente, relatar o contexto histórico que culminou no surgimento da OMC, posteriormente discorreu-se sobre a Organização para então ser abordada a questão da Justiça Comercial.

Como fonte para a presente pesquisa, utilizou-se do sítio eletrônico da OMC, bem como de bibliografias que tratavam da temática do comércio internacional e da justiça.

Quanto à metodologia da pesquisa, possui a natureza de uma pesquisa básica, pura. No que se diz respeito à abordagem do problema, tratou-se de uma pesquisa qualitativa. Do ponto de vista de seus fins, a pesquisa foi descritiva. O método de abordagem utilizado foi indutivo e o método de interpretação, gramatical. A técnica de pesquisa é essencialmente a bibliográfica e documental.

\section{FUNDAMENTAÇÃO TEÓRICA}

A fundamentação teórica se subdivide em quatro partes, seguindo a ordem de desenvolvimento do objeto do artigo. Em um primeiro momento, apresenta-se o contexto histórico que antecipou a criação da Organização Mundial do Comércio. Em sequência, discorre-se sobre a tentativa de criação da Organização Internacional do Comércio e o nascimento do GATT/47 bem como a criação da OMC. Por fim, aborda-se a Justiça nas relações comerciais relacionado a responsabilidade da Organização em sua busca.

\subsection{O contexto histórico que antecipou a criação da Organização Mundial do}

\section{Comércio (OMC)}


Para compreender o comércio internacional contemporâneo e suas instituições faz-se necessária discorrer sobre a situação das economias europeias nas últimas décadas do século XIX e nas primeiras décadas do século XX. Segundo TREBILCOCK e HOWSE (2005, p. 17), o surgimento das organizações internacionais instituídas com o escopo de administrar as relações mercantis deve ser compreendido como uma das faces de um processo mais amplo que resultaria em um aumento do acesso a mercados maiores e mais integrados.

Os mesmos autores destacam que as fronteiras nacionais, em meados do século XIX, eram as principais barreiras ao livre comércio entre as potências europeias. A primeira ruptura com o protecionismo do período anterior foi marcada pela revogação das Corn Laws, em 1846. Em seguida, ocorreu a redução e posterior abolição de tarifas incidentes sobre grande parte dos bens de consumo importados no Reino Unido.

À época, o Reino Unido era a mais relevante potência econômica. O país era o mundialmente o maior exportador de bens manufaturados, de bens de capital, além de grande prestador de serviços financeiros. Destarte, era o maio importador de produtos primários provenientes de nações em desenvolvimento, a exemplo do chá e do trigo.

Como efeito, as alterações sofridas internamente em suas condições políticas e econômicas geravam efeitos a nível global, de acordo com HOBSBAWN (2007. p. 64-65). Nesse ínterim, ensinam GILPIN e GILPIN (2001, p.196) que um dos pilares da hegemonia econômica britânica, o liberalismo econômico clássico, permeou as relações internacionais junto à revogação das Corn Laws, até os anos 1870. Iniciou-se, então, um aumento significativo das tarifas protecionistas.

A Grande Depressão fechou a longa era de liberalismo econômico, ao menos no que tange ao comércio de matérias-primas. Começando com a Alemanha e a Itália (têxteis) no final dos anos 1870, as tarifas protecionistas se tornaram um elemento permanente do cenário econômico internacional, culminando, no início dos anos 1890, com as tarifas punitivas associadas aos nomes de Méline, na França (1892) e McKinley, nos EUA (1890). (HOBSBAWN, 2007. p. 63-64)

O protecionismo acendeu, segundo GILPIN e GILPIN (2001, p.196), persistindo inclusive durante a Grande Depressão da década de 1930. TREBILCOCK e HOWSE (2005, p. 19) explicam que diante da diminuição da hegemonia de poder econômico, o Reino Unido perdeu sua capacidade impositiva perante seus parceiros comerciais dada a liberalização do comércio que acontecia nas primeiras décadas do século XIX. 
Diante deste cenário, surge a Primeira Guerra Mundial trazendo uma forte desorganização das relações comerciais internacionais. O conflito provocou o aumento abrupto do protecionismo, culminando em uma forte queda nos fluxos de mercantis entre os Estados.

Para TREBILCOCK e HOWSE (2005, p. 19), finda a guerra, os termos dos acordos de paz celebrados ao seu final contribuíram para o estabelecimento das políticas de desvalorização de câmbio e de restrições comerciais nos anos de 1920. Políticas, essas, que acarretariam no agravamento da crise econômica que teria seu ápice em 1929. Isso porque

(...) como comprovado que um excesso de protecionismo generalizado - que procura erguer barricadas em torno da economia de cada nação-Estado, por meio de fortificações políticas que a defendam do mundo exterior -é pernicioso para o crescimento econômico mundial. Isso seria pertinentemente provado entre as duas guerras mundiais. Entretanto, no período de 1880-1914, o protecionismo não era nem geral nem, com exceções ocasionais, proibitivo e, como vimos, restringia-se ao comércio de mercadorias (...). Calculou-se que o aumento global da produção entre 1880 e 1914 foi, por conseguinte, nitidamente maior do que fora durante as décadas de livre comércio. (TREBILCOCK, HOWSE, 2005, p. 19)

Logo, ainda que presente um aumento do protecionismo entre os anos de 1870 e 1914, isso não resultou em uma queda na produção mundial. Posteriormente, tal fato junto à redução dos fluxos mercantis internacionais que se instalou com a Primeira Guerra Mundial, gerou um novo período de crise econômica. Entende-se ainda que erros perpetrados na elaboração de políticas econômicas entre 1920 e 1940 foram causas remotas da Segunda Guerra Mundial.

Para JACKSON (2006), nas origens da eclosão do conflito estão a Grande Depressão, bem como os dispositivos do Tratado de Versalhes disciplinando a política de reparações aplicáveis à Alemanha. Durante a Grande Depressão dos anos 1930, houve um grande aprofundamento do processo de isolamento dos Estados, por intermédio do estabelecimento de barreiras comerciais cada vez maiores. Nesse período, destacam TREBILCOCK e HOWSE (2005, p. 19), o objetivo das nações era o de resguardar sua produção interna, o emprego de seus cidadãos, e tentar ao máximo blindar as suas moedas contra os efeitos maléficos da extensiva crise mundial. As políticas comerciais protecionistas dos anos 1930 foram alcunhadas de "empobreça o seu vizinho" (beggar-thy-neighbour). Esse apelido surgiu devido ao fato de que muitos países tentaram isolar a sua economia dos efeitos da crise, utilizando para tanto, aumento das barreiras ao comércio. O trágico resultado dessas políticas foi a intensa diminuição do comércio internacional e o sério agravamento da crise econômica. 
Verificou-se, segundo HOBSBAWN (1995, p. 94), uma queda de 60\% no comércio mundial em um período de quatro anos (1929-32).

O mesmo autor ainda discorre sobre como a gravidade da crise econômica fez com que os Estados adotassem medidas extremas, como a promulgação da tarifa Smoot-Hawley pelo congresso dos Estados Unidos da América em 1930, que determinou o aumento da alíquota do imposto de importação para 60\%. Esse aumento gerou represálias diretas de outros países, culminando na quase estagnação do comércio internacional. Outro exemplo foi o uso do princípio da nação mais favorecida ${ }^{2}$ que desapareceu de $60 \%$ dos 510 acordos comerciais internacionais celebrados entre os anos de 1931 e 1939. Nos acordos em que conseguiu sobreviver, assim o fez de maneira limitada. Em uma época de retração do comércio internacional, a ampliação do protecionismo esfriava as possibilidades de florescimento de um sistema multilateral de comércio de longo prazo.

Para GILPIN e GILPIN (2001, p.197), nos anos finais da Segunda Guerra Mundial, houve um novo período de expansão da liberalização comercial. O aprendizado adquirido pelos Estados durante a Grande Depressão da década de 1930 foi direcionado para a reconstrução da economia internacional.

Em julho de 1944, as potências aliadas já podiam prever que a Segunda Guerra Mundial cessaria em breve e decidiram coordenar esforços para a elaboração de táticas que pudessem ser empregadas na reconstrução da ordem econômica mundial no período do pósguerra, de acordo com TREBILCOCK e HOWSE (2005, p. 19). Nessa toda, entendeu-se que o isolamento econômico dos Estados era uma das causas subjacentes à eclosão dos conflitos e ao agravamento da Grande Depressão dos anos de 1930. Sob essa perspectiva, foi realizada no mesmo ano a Conferência de Bretton Woods, dirigida e organizada por ministros da fazenda dos Estados aliados. Não obstante, ficou reconhecida a necessidade de se criar uma organização internacional com mandato para regular as relações comerciais entre os países.

\subsection{A tentativa de criação da Organização Internacional do Comércio e o} nascimento do GATT/47

\footnotetext{
${ }^{2}$ Princípio do comércio interacional segundo o qual os Estados devem conferir o mesmo tratamento a todos os seus parceiros comerciais.
} 
Os autores TREBILCOCK e HOWSE (2005, p. 19) explicam que do acordo final firmado em Bretton Woods, criaram-se três organizações internacionais: o Fundo Monetário Internacional (FMI), com atribuição de promover a estabilidade do sistema financeiro internacional e de auxiliar países com crise na balança de pagamentos; o Banco Internacional para Reconstrução e Desenvolvimento (BIRD), cuja finalidade inicial seria a de financiar a reconstrução dos países europeus no pós-guerra; e a Organização Internacional do Comércio (OIC), cuja responsabilidade seria a supervisão das negociações e administração dos acordos celebrados no que seria um novo sistema multilateral de comércio.

Os mesmos autores continuam seus ensinamentos ao descrever que, embora os EUA e o Reino Unido tivessem celebrado acordos apresentando objetivos comuns de política comercial antes da realização de Bretton Woods, divergências em pontos basilares da agenda levaram ao enfraquecimento das negociações para a criação da OIC nos anos que se seguiram à Conferência. O Reino Unido relutava em reduzir barreiras comerciais, uma vez que isso contrariava o sistema de preferências imperiais e lesaria as relações ainda mantidas com os Estados que compunham o Império Britânico. Soma-se a isso o fato de o parlamento defendia restrições quantitativas às importações, como forma de proteger a produção interna. Nos EUA, por razões de política interna, o congresso limitou a capacidade de o presidente negociar reduções tarifarias multilateralmente. Assim, a proposta norte-americana na conferência foi de reduções tarifárias negociadas bilateralmente, produto a produto. Os benefícios acordados em tal negociação seriam posteriormente estendidos aos demais Estados membros da organização que se pretendia criar, por intermédio da utilização do princípio da nação mais favorecida.

Havia, portanto, segundo GILPIN e GILPIN (2001, p.217-218) um conflito entre os interesses norte-americanos e britânicos na conferência de Bretton Woods. De um lado, os negociadores norte-americanos advogavam pelo livre comércio e pelo acesso imediato a mercados estrangeiros. Já os negociadores britânicos, ainda que comprometidos com o ideal do livre comércio, eram relutantes com relação à perda de autonomia quanto à adoção de certas políticas econômicas aptas a fomentar o desenvolvimento internamente. Em 1946, partiria dos EUA a intenção de realização uma conferência geral sobre comércio e emprego, que deveria se realizar no contexto do Conselho Econômico e Social das Nações Unidas 
(ECOSOC). O principal objetivo dessa conferência seria o de elaborar a carta constitutiva da OIC.

A Carta não incluiria reduções tarifárias específicas. A ideia era criar posteriormente, um protocolo a ser anexado, incluindo todos os acordos de redução tarifária negociados entre os Estados parte. Esse protocolo concretizou-se na forma do Acordo Geral sobre Tarifas e Comércio (GATT/1947). As negociações da carta constitutiva da OIC e do GATT/1947 ocorreram paralelamente no âmbito da Organização das Nações Unidas (ONU).

\begin{abstract}
Ela [a Carta de Havana] foi negociada ao longo de um período de dois anos, de 1946 a 1948, em uma série de reuniões em Londres, Nova York, Genebra, e finalmente na Conferência das Nações Unidas sobre Comércio e Emprego em Havana, que produziu a "Carta de Havana para a Organização Internacional do Comércio". Como o nome da conferência sugere, a OIC abrangia não apenas política comercial, mas também política trabalhistas. Adicionalmente, cobria acordos sobre commodities, desenvolvimento econômico, e práticas negociais restritivas. Enquanto os dispositivos mais ambiciosos da OIC estavam sendo negociados, no entanto, os governos estavam interessados em relaxar tarifas e outras restrições de forma mais rápida. (PALMETER. MAVROIDS, 2004)
\end{abstract}

A minuta inicial, conforme ISMAIL (2011), da Carta da OIC foi apresentada pelos EUA como resultado de negociações bilaterais ocorridas anteriormente com o Reino Unido, apresentando disposições extremamente favoráveis aos países de desenvolvimento avançado. O Brasil também apresentou uma minuta de Carta, mas propôs que apenas os países desenvolvidos aderissem incondicionalmente ao princípio da nação mais favorecida. Propugnou também pelo reconhecimento da necessidade de adoção de medidas especiais para redução de assimetrias entre os futuros membros. Essas propostas foram repelidas pelo governo dos EUA.

De acordo com IRWIN, MAVROIDS, SYKES (2008), na Conferência Preparatória de Genebra, ocorrida em abril a outubro de 1947, a redação do GATT/1947 foi finalizada e o Acordo foi implementado. Foram celebrados, na ocasião, 123 pactos, regulamentando a tarifação do que correspondia à metade do comércio mundial à época. O estabelecimento de reduções tarifárias, ainda que modesto, representou uma grande mudança na política comercial do período pós-guerras.

ISMAIL (2011) ensina que dos vinte e três membros originários do GATT/1947, dez eram países em desenvolvimento. Porém, o Acordo apresentava poucos mecanismos de redução de assimetrias entre Estados, até porque, à época, a maioria dos países em 
desenvolvimento era colônias dos países desenvolvidos. Após a entrada em vigor do GATT/1947, em $1^{\circ}$ de janeiro de 1948, os Estados contratantes se reuniram em Havana, Cuba, com o intuito de elaborar a redação final do documento que instituiria a OIC e ainda reformar alguns dispositivos do próprio GATT/1947. No início da Conferência de Havana houve protestos por parte dos representantes dos Estados em desenvolvimento que acreditavam que a minuta de Carta constitutiva da OIC, apresentada após a Conferência de Genebra, privilegiava somente os interesses das grandes potências industriais. $\mathrm{O}$ almejado pelos países em desenvolvimento nas negociações, em especial Austrália, Índia, China, Brasil e Chile, era o de voltar as atenções nas negociações para a necessidade de geração de emprego e de desenvolvimento econômico. Esse grupo de países alegava que o tratado constitutivo proposto reduziria drasticamente a capacidade de as nações estabeleceram políticas de desenvolvimento, como a adoção de restrições quantitativas às importações para proteção da sua recente indústria. Importante salientar que, desde o início das negociações do GATT/1947, as negociações sempre foram capitaneadas pelos Estados de maior poderio econômico. Um exemplo disso é o fato dos EUA e o Reino Unido iniciarem acordos de políticas comerciais antes mesmo da realização da Conferência de Bretton Woods.

Destacam IRWIN, MAVROIDS, SYKES (2008), que o embate entre os interesses das potências industriais e dos países em desenvolvimento aliado às dificuldades de negociações das políticas econômica e comercial dos EUA e Reino Unido era forte indicativo de que a OIC dificilmente viria a ser constituída. Ainda assim, o intento dos Estados presentes em Havana era a de que o GATT/1947 integrasse o arcabouço normativo da OIC. Desse modo, a prioridade durante a Conferência de Havana era a de concluir a redação do tratado constitutivo da organização. Muitos dispositivos do GATT/1947 foram revistos durante o encontro, principalmente em face do posicionamento contrário exposto pelos países em desenvolvimento.

Ainda segundo os autores IRWIN, MAVROIDS, SYKES (2008), por conta da Guerra Fria, o ambiente político otimista nos EUA sofreu transformações ainda durante os primeiros anos das negociações. Em dezembro de 1950, a administração Truman retirou a Carta de Havana da pauta de apreciação do congresso norte-americano, resultando, assim, no fim definitivo das negociações para a criação da organização. Havia a possibilidade de os demais Estados continuarem as negociações para a criação da OIC, no entanto, os EUA emergem da 
Segunda Guerra Mundial como potência econômica hegemônica. Logo, uma organização internacional do comércio que não contasse com a participação do mais proeminente ator internacional não era desejada.

$\mathrm{Na}$ ausência da OIC, coube ao GATT/1947 regular de forma provisória as relações comerciais internacionais por quarenta e sete anos.

O GATT provou ser extremamente bem-sucedido no fomento da liberalização do comércio e no fornecimento de uma estrutura para discussões comerciais. Porém, ao contrário da abandonada OIC, sua autoridade e o escopo de suas responsabilidades eram severamente limitados; era essencialmente um fórum de negociações ao invés de uma verdadeira organização internacional, e não tinha autoridade regulatória (rule-making). Além disso, ele carecia de um mecanismo de solução de controvérsias adequado, e a sua jurisdição era exercida principalmente sobre bens manufaturados. O GATT não tinha autoridade para lidar com agricultura, serviços, direitos de propriedade intelectual, ou investimento estrangeiro direto; tampouco tinha o GATT autoridade suficiente para lidar com uniões aduaneiras e outros acordos preferenciais de comércio. (GILPIN, GILPIN, 2001, p.218)

O GATT/1947 surge como um acordo temporário. Tanto que foi integrado ao ordenamento jurídico internacional por intermédio de um Protocolo de Aplicação Provisória que deveria vigorar enquanto a Carta da OIC não fosse formalmente adotada. Assim sendo, o Acordo continha poucos dispositivos institucionais e pouco discorria sobre solução de controvérsias. Além disso, a entrada em vigor por meio de um protocolo provisório possibilitou sua adoção pelas nações sem que fosse submetido ao escrutínio dos processos constitucionais para a ratificação de tratados.

Inicialmente, os Estados que aderiram ao Protocolo de Aplicação Provisória anuíram em aplicar as Partes I e III do GATT/1947 em toda a sua extensão e a Parte II quando não inconsistente com as suas legislações internas ${ }^{3}$. A Parte I incorpora o princípio da nação mais favorecida e o cronograma de reduções tarifárias, ao passo que a Parte III dispõe sobre a administração do Acordo. A Parte II, cuja obrigatoriedade era limitada pelas leis internas dos Estados, apresenta a parte mais substantiva das normas do GATT/1947. A despeito de seu caráter provisório, as nações contratantes fizeram inúmeras concessões para aderir ao Acordo. A sua utilidade para os governos era maior do que os problemas eventualmente decorrentes da falta de um arcabouço institucional bem estabelecido. O posicionamento pouco usual adotado pelas partes negociantes naquele tempo era representativo do entendimento segundo o qual,

${ }^{3}$ Protocol of Provisional Application of The General Agreement on Tariffs And Trade. Arts. 1 (a) e (b). Disponível em: https://www.wto.org/english/docs_e/legal_e/gatt47_e.pdf Último acesso em: 20 de outubro de 2019. 
em matéria comercial, as formalidades jurídicas podem ser deixadas para um outro dia. Nos anos que se seguiram à implementação do Acordo, a necessidade de se estabelecer uma instituição sólida, com regras claras e transparentes, tornou-se latente.

À época de sua assinatura, de acordo com GILPIN e GILPIN (2001, p. 218), o GATT/1947 era essencialmente um foro de negociações, com escassa capacidade legislativa (rule-making authority). Ademais, o Acordo não previa um sistema de solução de controvérsias bem estruturado, com fases e prazos definidos. A sua jurisdição era exercida principalmente sobre produtos manufaturados deixando de fora temas como agricultura e serviços. Ainda que com suas limitações, o Acordo foi um importante instrumento na redução de barreiras ao comércio internacional. A designação de normas, ainda que esparsas e aptas a regular um número limitado de situações jurídicas, representou um avanço na redução de conflitos relacionados com o comércio. A necessidade de adensamento desse conjunto normativo, bem como de criação de instituições aptas a geri-lo, tornou-se manifesta nos anos que se seguiram à sua implementação. No período em que esteve em vigor, o GATT/47 passou a desempenhar progressivamente as funções que seriam atribuídas à OIC, permitindo que o GATT/47 fosse se adaptando e preenchendo a lacuna institucional existente até a criação da Organização Mundial do Comércio (OMC).

\subsection{A criação da Organização Mundial do Comércio}

O Acordo de Marrakesh que estabeleceu a Organização Mundial do Comércio foi assinado em 15 de abril de 1994, entrando em vigor em $1^{\circ}$ de janeiro de 1995.

\footnotetext{
Enquanto o GATT foi um acordo apoiado por um secretariado, a OMC é uma organização associativa que aumenta a coerência jurídica por meio de seus direitos e obrigações abrangentes e do estabelecimento de um fórum permanente para negociações. Reuniões ministeriais bianuais deveriam aumentar a orientação política da instituição. A Rodada do Uruguai também criou um mecanismo de revisão de políticas para monitorar os Estados membros. (GILPIN E GILPIN, 2001, p.223)
}

De modo geral, a Organização é um fórum de negociação de políticas comerciais, com vistas ao estabelecimento de normas de conduta comuns entre seus Estados membros. Seus acordos constitutivos abarcam normas jurídicas mínimas cujo propósito é o de regular os intercâmbios mercantis internacionais. Cabe mencionar como principais instrumentos, o 
Acordo Geral de Tarifas e Comércio de 1994 (GATT/1994), o Acordo Geral de Comércio de Serviços (GATS) e o Acordo sobre Aspectos dos Direitos de Propriedade Intelectual Relacionados ao Comércio (TRIPS). A implementação desses acordos se dá à luz dos princípios e objetivos institucionais. Para tanto, é necessário considerar não apenas o texto dos acordos constitutivos da OMC, incluindo os seus preâmbulos, mas também do GATT/1947:

Reconhecendo que suas relações no domínio comercial e econômico devem ser orientadas no sentido de elevar os padrões de vida, de assegurar o emprego pleno e um alto e sempre crescente nível de rendimento real e de procura efetiva, para a mais ampla exploração dos recursos mundiais e a expansão da produção e das trocas de mercadorias; Almejando contribuir para a consecução desses objetivos, mediante a conclusão de acordos recíprocos e mutuamente vantajosos, visando à redução substancial das tarifas aduaneiras e de outras barreiras às permutas comerciais e à eliminação do tratamento discriminatório, em matéria de comércio internacional. ${ }^{5}$

O preâmbulo do Acordo de Marrakesh compreende grande parte do texto do preâmbulo do GATT/1947, acrescendo novos objetivos e propósitos:

\begin{abstract}
Reconhecendo que as suas relações na esfera da atividade comercial e econômica devem objetivar a elevação dos níveis de vida, o pleno emprego e um volume considerável e em constante elevação de receitas reais e demanda efetiva, o aumento da produção e do comércio de bens e serviços, permitindo ao mesmo tempo a utilização ótima dos recursos mundiais em conformidade com o objetivo de um desenvolvimento sustentável e buscando proteger e preservar o meio ambiente e incrementar os meios para fazê-lo, de maneira compatível com suas respectivas necessidades e interesses segundo os diferentes níveis de desenvolvimento econômico. ${ }^{6}$
\end{abstract}

Assim, nota-se que o GATT/1947 fora constituído com o propósito de fomentar o desenvolvimento, aumentando o bem-estar das populações. No texto do preâmbulo do acordo constitutivo da OMC, encontra-se o mesmo objetivo fundamental de promoção do desenvolvimento econômico de seus Estados membros, por meio do estabelecimento de normas de comércio internacional, acrescido de novos temas, como a necessidade de preservação do meio ambiente e de redução da pobreza. Dessa forma, a expansão das relações comerciais, pautadas em um conjunto de normas jurídicas comum aos seus Estados membros, deve orientar a promoção do crescimento econômico de todos os parceiros comerciais.

${ }^{4} \mathrm{O}$ GATT/47 foi atualizado e incorporado às normas da OMC como GATT/94.

${ }^{5}$ Acordo Geral Sobre Tarifas e Comércio, como incorporado por meio da Lei 313 de 30 de julho de 1948. Disponível em: http://www.planalto.gov.br/ccivil 03/leis/1930-1949/L313.htm. Último acesso: 20 de setembro de 2020.

${ }^{6}$ Ata Final que Incorpora os Resultados das Negociações Comerciais Multilaterais da Rodada Uruguai, conforme incorporado pelo Decreto 1.355 de 30 de dezembro de 1994. Disponível em: http://www.planalto.gov.br/ccivil_03/decreto/1990-1994/anexo/and1355-94.pdf. Último acesso: 20 de setembro de 2020. 
Para MARCEAU, PORGES, BAKER (2015), é condição para os Estados ingressarem na Organização a adesão a total a todos os acordos multilaterais concluídos com a Rodada do Uruguai $^{7}$, ao contrário do que ocorria sob o GATT/1947. Isso culmina, por exemplo, no aumento da complexidade das normas internas dos Membros. Outra alteração significativa se refere à resolução de disputas. Sob o GATT/47, desenvolveu-se um mecanismo de solução de controvérsias de características eminentemente diplomáticas, que não impunha a observância de prazos e cujas decisões eram facilmente bloqueadas. Isso permitia que os casos se arrastassem por anos sem solução. O sistema de solução de controvérsias (SSC) da OMC, por sua vez, é baseado em regras e etapas claramente definidas, com prazos determinados para a conclusão de cada uma das suas fases.

Ressalte-se que, segundo LEITNER, LESTER (2015), o objetivo do SSC é dirimir conflitos, em especial por intermédio de consultas, e não o de fazer coisa julgada. Corrobora esse entendimento o fato de que, até janeiro de 2015, apenas 162 (cento e sessenta e duas) das 488 (quatrocentas e oitenta e oito) consultas iniciadas completaram todo o processo do painel. A maior parte dos outros casos foi resolvida por meio de acordo, ou continua na fase de consultas.

A OMC nasceu de negociações e tudo o que a OMC faz é resultado de negociações. Atualmente, a OMC é sede de novas negociações, no âmbito da "Agenda de Desenvolvimento de Doha", lançada em 2001. No coração, estão os acordos da OMC, negociados e assinados pela maior parte das nações comerciais do mundo. Esses documentos fornecem as regras básicas legais para o comércio internacional. São essencialmente contratos, obrigando os governos a manter suas políticas comerciais dentro dos limites acordados. A própria Organização afirma que embora negociado e assinado pelos governos, o objetivo é ajudar os produtores de bens e serviços, exportadores e importadores a conduzir seus negócios, enquanto permite que os governos cumpram os objetivos sociais e ambientais. Coloca ainda que o principal objetivo do sistema é ajudar o comércio a fluir o mais livremente possível desde que não haja efeitos colaterais indesejáveis - a fim de promover o desenvolvimento econômico e o bem-estar. Em parte, isso significa remover obstáculos. Significa também garantir que indivíduos, empresas e governos saibam quais são as regras comerciais em todo o mundo e dando a eles a confiança de que não haverá mudanças repentinas de política. Em

\footnotetext{
${ }^{7}$ Princípio do single undertaking.
} 
outras palavras, as regras devem ser "transparentes" e previsíveis. Os acordos, incluindo os minuciosamente negociados no sistema da OMC, devem ser interpretados da maneira mais harmoniosa para que se resolva a controvérsia por intermédio de um procedimento neutro, baseado em uma base legal acordada. Esse é o objetivo por trás do processo de solução de controvérsias escrito nos acordos da OMC. ${ }^{8}$

Ainda sobre a OMC ter como objetivo fomentar o comércio a fluir livremente, mas tendo ao mesmo tempo o zelo por evitar efeitos indesejados, esses efeitos são aqueles de impedem ou dificultam o equilíbrio nas relações comerciais, induzem a manutenção de disparidades entre países desenvolvidos e em desenvolvimento que têm, em geral, reflexos diretos no bem-estar de seus cidadãos. Ou seja, de certa forma, parece estar no escopo desse objetivo principal a busca por alcançar parâmetros de justiça nessas relações comerciais internacionais.

\subsection{A Justiça nas Relações Comerciais}

Para Aristóteles a justiça das trocas comerciais era baseada em contratos. Quando há uma relação contratual bilateral de cunho mercantilista, os sujeitos se norteiam por uma reciprocidade proporcional, uma proporcionalidade cuja finalidade é manter a ordem e a boa relação entre esses sujeitos.

Os homens procuram retribuir o mal com o mal (e se não podem fazê-lo, sentem-se reduzidos à condição de escravos), e o bem com o bem (e se não podem fazê-lo não haverá troca, e é pela troca que eles se mantêm unidos). É por essa razão que os homens dão uma posição de destaque ao Templo das Graças: para promover a retribuição de seus serviços. Com efeito, esta é uma das características da graça, e deveríamos retribuir ao que nos dispensou a graça, tomando a iniciativa de lhe fazer o mesmo, em outra ocasião. A retribuição proporcional se faz pela conjunção cruzada, por exemplo, suponhamos que A é um arquiteto, B um sapateiro, C uma casa e D um par de sapatos. $\mathrm{O}$ arquiteto deve receber do sapateiro o produto do trabalho deste, e dar-lhe o seu em retribuição. Se houver uma igualdade proporcional de bens e ocorrer uma ação recíproca, o resultado que mencionamos será verificado. Se não for assim, a permuta não será igual, nem válida, pois nada impede que o trabalho de um seja superior ao do outro, e neste caso, os produtos terão de ser igualados. (ARISTÓTELES, 2015)

${ }^{8}$ WORLD TRADE ORGANIZATION.About the WTO. 2019. Disponível em: $<$ https://www.wto.org/english/thewto_e/whatis_e/who_we_are_e.htm>. Acesso em: 20 de setembro de 2020. 
Logo, a reciprocidade é um fator decisivo nas relações de troca de serviços e mercadorias. Além disso, o desequilíbrio e a desproporcionalidade nessa relação acarretaria em um colapso da ordem social, o que levaria a polis ao caos. A fim de manter a proporcionalidade e a reciprocidade, os produtos e serviços necessitam de um mecanismo de comparação. Nesse ínterim, Aristóteles aborda a questão monetária, ou seja, o dinheiro.

Eis a razão pela qual todas as coisas que são objeto de troca devem ser comparáveis
de algum modo, e para esta finalidade foi instituído o dinheiro, o qual, de um modo
geral, se torna um meio termo, visto que mede todas as coisas e, por consequência,
também o excesso e a falta (por exemplo, quantos pares de sapatos são iguais a uma
casa ou a uma determinada quantidade de alimento).(...) Mas o dinheiro tornou-se,
por convenção, uma espécie de representante da procura, e se chama dinheiro
(nômisma) porque existe, não por natureza, mas por lei (nomos), e está em nosso
poder muda-lo e torna-lo sem valor.(...) Mas com o dinheiro ocorre a mesma coisa
que com os bens: ele não tem sempre o mesmo valor; porém, tende a ser mais
estável. Por isso é necessário que todos os bens tenham um preço estipulado, pois
assim haverá sempre troca e, consequentemente, associação entre os homens.
(ARISTÓTELES, 2015)

Destrinchar a questão da justiça no comércio não foi o foco principal das discussões aristotélicas. Na realidade o filósofo evidencia que não existe virtude moral na Justiça Comercial. Adentrando nos assuntos comerciais, entendia que "Não foi, pois, a natureza que criou o comércio que consiste em comprar para vender mais caro" (ARISTÓTELES, 1977, p.21). Parte-se daqui a compreensão da forma pela qual o filósofo entendia a natureza do comércio e também moeda. Na realidade essa última, não passa de uma ficção valorada à disposição do mercado. $\mathrm{O}$ tratamento dado por Aristóteles à moeda é de fato muito similar ao tratamento atualmente adotado. Interessante ainda que o filósofo não considera o dinheiro uma justiça completa, mas apenas como uma espécie de "regulador" da máquina econômica.

Pode-se então relacionar a necessidade do dinheiro à necessidade de Justiça comercial, sendo que o dinheiro se apresenta como um meio e não um fim dessa justiça. A moeda se apresenta como uma possibilitadora das trocas, dos contratos, visando assim, a sua proporcionalidade, ou seja, a troca justa. Para que isso ocorra, é necessária a valoração dos bens ou serviços a serem comutados na relação contratual em pauta. Esse mecanismo permite maior estabilidade e praticidade na permuta. O dinheiro é feito e regulado pela lei, e tem como princípio servir ao homem. Aristóteles discorre sobre a relação legislativa do dinheiro ao afirmar que o valor do dinheiro “(...) consiste no que a lei lhe confere. Logo que mude a opinião daqueles que o usam, deixará de ter qualquer utilidade e já não servirá para conseguir a menor das coisas necessárias à vida." (ARISTÓTELES. 1977.p. 21). Dessa forma, a o 
dinheiro pode ser resumido como um instrumento legal, criado por sua estabilidade e praticidade, usado no comércio com a finalidade de garantir transações reciprocamente proporcionais. Seu surgimento diminuiu o que os economistas denominam de custos transacionais do comércio.

Aristóteles continua ao ensinar que como uma solução prática em substituição ao escambo, ao oferecer estabilidade e facilidade, a utilização do dinheiro permitiu o florescimento e fortalecimento da atividade comercial que é até os dias atuais, uma das principais e mais importante atividades da humanidade. $\mathrm{O}$ dinheiro permitiu aos indivíduos valorar e quantificar seus bens e serviços e assim, coloca-los no giro do mercado. É seguro afirmar que o dinheiro está em uma segunda categoria de importância para Aristóteles, apesar do reconhecimento pelo autor de suas utilidades. O dinheiro pode ser algo convencionado para além da sua finalidade natural, de fácil manejo, usando-se assim ouro, ferro, bronze ou outros tipos de materiais.

O pensador ainda relata que a necessidade da troca nasce da relação de abundância e escassez e ganha ainda maior destaque frente à instituição das propriedades. Assim, não existe troca sem propriedade. A troca, de acordo com Aristóteles, é um instrumento de civilizações menos evoluídas. As grandes civilizações alicerçaram suas trocas no sistema de comércio, guiado pela razão e pelo uso da moeda. Por intermédio do comércio era possível a obtenção de garantias e seguranças outrora não asseguradas. Com o advento do mercado, o transporte se desenvolveu, e a compra e venda de produtos galgou seu espaço. Com a finalidade de garantir a reciprocidade desses contratos foi estabelecida a moeda como uma solução fácil de manejar, estável, proporcionalmente recíproca e previamente valorada, não sendo mais necessário pesar ou avaliar seu valor. Destarte, a moeda nasce da necessidade do comércio, sendo ainda que mercado e comércio coexistem simbioticamente.

Tendo sido, portanto, inventada a moeda por uma necessidade de comércio, daí nasceu uma nova maneira de comerciar e adquirir: no princípio, bastante simples; depois, com o passar do tempo, mais complicada, quando se começou a perceber donde e de que modo se podia conseguir o maior benefício possível. É este proveito pecuniário que ela procura; só se preocupa em procurar donde pode vir mais dinheiro: é a mãe das grandes fortunas. Na realidade, comummente faz-se consistir a riqueza na grande quantidade de dinheiro. (ARISTÓTELES, 1977, p. 22-23)

Sob essa ótica, entende-se que o dinheiro gera mais dinheiro, culminando em grandes fortunas. Com a lógica do maior benefício, perde-se o foco em qualquer outro aspecto que não 
seja a geração de mais dinheiro. Percebe-se então a posição aristotélica sobre o dinheiro e a sua conexão com a desigualdade e a crítica ao comércio preocupar-se único e exclusivamente com a busca incessante pelo acúmulo pecuniário. A falta de finalidade na criação de fortunas, a ausência de uma vida de paixão e ganância desenfreada é condenada por Aristóteles.

O dinheiro serve-lhes para dois usos análogos e alternativos: um deles, comprar as coisas para as tornar a vender mais caras; outro, emprestar para receber no prazo fixado o capital juntamente com os juros. Estes dois ramos do seu comércio não se distinguem, como se constata, senão na medida em que num deles se usam as coisas como meio para aumentar o dinheiro, enquanto no outro é o próprio dinheiro que serve imediatamente para aumentar a si mesmo. (ARISTÓTELES, 1977, p. 23)

Em suma, o dinheiro é vazio de virtude ou finalidade. Para o filósofo, a busca exclusivamente pelo acúmulo do dinheiro, algo vazio e falso por natureza jamais permitirá alcançar a boa vida. Essa existência seria uma vida sem limites, uma vida desvirtuada, que não busca a felicidade e não se coloca limites. É um viver, mas nunca um viver bem, pois falta justiça. Essa vida de paixão leva invariavelmente à busca de prazeres ligados a uma vida animal e usa-se da pecúnia na busca por estes prazeres.

Conclui-se então que, o dinheiro que gera dinheiro é apenas um meio de obtenção de prazeres imediatos, pautado na ganância daqueles que abusam da natureza ilimitada da moeda. A problemática reside no fato de que onde existe acúmulo de um lado, existe falta no outro. Logo a existência de grandes fortunas acarreta na existência de falta de recursos para outros, o seja, um desequilíbrio nas relações entre os homens. É papel da Justiça corrigir estas irregularidades, a fim de se garantir a saúde da sociedade e a igualdade entre os cidadãos. $\mathrm{O}$ filósofo ao condenar o acúmulo de dinheiro, a criação das grandes fortunas e a criação da moeda pela moeda através do comércio está na realidade condenando o desequilíbrio gerado nas relações dos membros da comunidade política. Esse desequilíbrio é injusto. Assim, o mero acúmulo de moeda é uma fonte de desigualdade, e a desigualdade deve ser combatida para que se obtenha o exercício da Justiça.

A intensa desigualdade socioeconômica cria uma desproporcionalidade imensa entre os mais ricos, e os mais pobres. Isso acarreta em problemas sociais, como a violência, a ausência de educação básica e cuidados com a saúde e condições parcas de habitação e lazer. Pensadores como Amartya Sen inclusive tratam deste problema, alinhando a questão de uma redistribuição justa de riquezas como o caminho para a liberdade. Sen apresenta uma variedade de argumentos para esta afirmação, entre elas afirma que 
O desenvolvimento requer que se removam as principais fontes de privação da liberdade: pobreza e tirania, carência de oportunidades econômicas e destituição social sistemática, negligência dos serviços públicos e intolerância ou interferência excessiva de Estados repressivos. A despeito de aumentos sem precedentes na opulência global, o mundo atual nega liberdades elementares a um grande número de pessoas - talvez até mesmo a maioria. Às vezes a ausência de liberdades substantivas relaciona-se diretamente com a pobreza econômica, que rouba das pessoas a liberdade de saciar a fome, de obter uma nutrição satisfatória ou remédios para doenças tratáveis, a oportunidade de vestir-se ou morar de modo apropriado, de ter acesso a água tratada ou saneamento básico. (SEN, 2010, p.16-17)

Novamente destaca-se a questão do acúmulo. O acúmulo gera vulnerabilidade social, uma vez que a riqueza de uns gera a pobreza de outros, privando os vulneráveis suas necessidades mais básicas. Como a distribuição de riquezas se dá por intermédio do comércio, faz-se relevante que a Organização Mundial do Comércio tenha consciência do seu papel enquanto vetor de redistribuição ao olhar para os países que foram privados de acúmulo de riquezas para que os países já hegemônicos pudessem garantir o seu status dominante. A responsabilidade da Organização é latente. Por intermédio de suas regras, princípio e sob o escopo de seu objetivo enquanto órgão internacional, deve visar promover a inclusão dos países em desenvolvimento e deve facilitar as trocas comerciais para esses países possam garantir o desenvolvimento do comércio enquanto desencadeador de redistribuição de riqueza. Não deve servir apenas como instrumento de política externa aos países hegemônicos e tampouco deve se abster em gerir as demandas do grupo de países menos favorecidos. Até porque esse último grupo de países possuem uma maior necessidade de se utilizar do comércio como instrumento possibilitador de desenvolvimento, gerador de riqueza e proporcionador de uma melhor vida aos seus cidadãos.

\section{CONCLUSÃO}

Cabe ressaltar que a hipótese inicialmente apresentada foi confirmada quando percebida que há no escopo dos objetivos da OMC a finalidade de promoção de justiça comercial devendo ter um olhar atencioso ao grupo países não hegemônicos. Na prática, a realidade da disparidade social permite observar que esse objetivo ainda necessita de esforços no sentido de tentar proporcionar uma justiça comercial em especial aos países periféricos. 
Para que houvesse essa compreensão, iniciou-se primeiramente um relato do contexto histórico que culminou no surgimento da OMC, posteriormente discorreu-se sobre a Organização para então ser abordada a questão da Justiça Comercial.

O GATT/47, ainda que limitado, serviu como um acordo capaz de reduzir barreiras ao comércio internacional. Enquanto em vigor, o Acordo desempenhou parte das funções que foram pensadas para a OIC, até a criação da Organização Mundial do Comércio (OMC). Dessa forma, conclui-se que tanto o GATT quanto a OMC foram pensados com o propósito de fomentar o desenvolvimento e bem-estar das populações dos seus membros. Pode-se, então, compreender que a expansão das relações comerciais, pautadas em um conjunto de normas jurídicas preconizadas pela Organização visa promover o crescimento econômico de todos os parceiros comerciais. Importante também salientar que como a OMC nasceu de negociações e tudo faz é resultado de negociações, suas regras devem ser "transparentes" e previsíveis.

Fica evidente a responsabilidade da Organização em especial, no que infere o seu papel enquanto promotora da inclusão dos países em desenvolvimento, sendo que deve ser capaz de auxiliar com especial atenção as trocas comerciais para esses países não hegemônicos que enxergam no comércio internacional um meio capaz de possibilitar desenvolvimento, gerar riqueza e proporcionador de uma melhor condição de vida aos seus cidadãos.

Reforça-se, por fim, que a pesquisa descritiva se manteve de natureza de básica, pura. O problema foi abordado de forma qualitativa cujo método de abordagem indutivo com interpretação gramatical. A técnica de pesquisa é essencialmente a bibliográfica e documental.

\section{REFERÊNCIAS}

ARISTÓTELES. Tratado da Política. Livros de Bolso Europa-América: Porto, 1977

ARISTÓTELES. A Política. Tradução de Nestor Silveira Chaves. Ed. Especial. Rio de Janeiro: Nova Fronteira, 2017.

ARISTÓTELES. Ética à Nicômaco. Coleção a Obra Prima de Cada Autor. Tradução de Luciano Ferreira de Souza. Martin Claret: São Paulo, 2015. 
DIXIT, Avinash K. The Making of Economic Policy: A Transaction-Cost Politics Perspective. Cambridge: MIT Press, 1996.

FOREMAN-PECK, James. A History of the World Economy. Ottawa: Barnes \& Noble, 1983.

GILPIN, Robert; GILPIN, Jean M. Global Political Economy - Understanding the International Economic Order. Princeton: Princeton University Press, 2001.

HOBSBAWN, Eric. A Era dos Impérios: 1875-1914. 11ª ed. São Paulo: Editora Paz e Terra S/A, 2007.

HOBSBAWN, Eric. The Age of Extremes: The Short Twentieth Century 19141991. Londres: Abacus, 1995.

IRWIN, Douglas A. Free Trade Under Fire. Princeton: Princeton University Press, 2002.

IRWIN, Douglas A. MAVROIDIS, Peter C. SYKES, Alan O. The Genesis of GATT. Nova York: Cambridge University Press, 2008.

ISMAIL, Faizel. Rediscovering the Role of Developing Countries in the GATT. In: LEE, YongShik.

HOEKMAN, Bernard M. e MAVROIDIS, Petros C. The World Trade Organization: law, economics and politics. Nova Iorque: Routledge, 2007.

JACKSON, John H. Global Economics and International Economic Law. Journal of International Economic Law. V. 1, Pgs. 1-23, 1998. JACKSON, John H. Sovereignty, the WTO, and Changing Fundamentals of International Law. Nova York: Cambridge University Press, 2006.

JACKSON, John H. The Perils of Globalization and the World Trading System. Fordham International Law Journal. 24, no. 1 (2000): 371-382. JACKSON, John H. The Jurisprudence of GATT and the WTO: insights on treaty law and economic relations. Cambridge: Cambridge University Press, 2000.

JACKSON, John H. The World Trading System: law and policy of international economic relations. Boston: Massachussets Institute of Technology Press, 1997.

LEITNER, Kara. LESTER, Simon. WTO Dispute Settlement 1995-2014-A Statistical Analysis. Journal of International Economic Law. 2015, 18, 203-214

MARCEAU, Gabrielle. PORGES, Amelia. BAKER, Daniel Ari. Introduction and Overview. In: MARCEAU, Gabrielle. A History of Law and Lawyers in the GATT/WTO The Development of the Rule of Law in the Multilateral Trading System. Nova York: Cambridge University Press, 2015 
PALMETER, David; MAVROIDS, Petros C. Dispute Settlement in the World Trade Organization: Practice and Procedure. $2^{\mathrm{a}}$ ed. Cambridge: Cambridge University Press, 2004.

SEN, Amartya. Desenvolvimento Como Liberdade. Companhia de Bolso: São Paulo, 2010

TREBILCOCK, Michael. Between Theories of Trade and Development: the future of the world trading system. The Robert Hudec Public Lecture. Society for International Economic Law. 24 de julho de 2014.

TREBILCOCK, Michael. J. CHANDLER, Marsha A. HOWSE, Robert. Trade and transitions: a comparative analysis of adjustment policies. Londres: Routledge, 1990.

TREBILCOCK, Michael J. HOWSE, Robert. The Regulation of International Trade. $2^{\mathrm{a}}$ ed. Nova York: Routledge, 2005. 